\title{
Aleitamento materno no contexto da Covid-19
}

\author{
Breastfeeding in the context of Covid-19 \\ Lactancia materna en el contexto de Covid-19
}

Recebido: 08/05/2021 | Revisado: 16/05/2021 | Aceito: 07/07/2021 | Publicado: 17/07/2021

\author{
Wanessa Nobre do Carmo Glória \\ ORCID: https://orcid.org/0000-0001-5207-4229 \\ Fundação Santa Casa de Misericórdia do Pará, Brasil \\ E-mail: wanessanobre19@gmail.com \\ Amanda Ouriques de Gouveia \\ ORCID: https://orcid.org/0000-0002-6874-8352 \\ Fundação Santa Casa de Misericórdia do Pará, Brasil \\ E-mail: enf.amandaouriques@ hotmail.com \\ Ellaine Valéria Araújo da Silva Lima \\ ORCID: https://orcid.org/0000-0001-9426-4354 \\ Fundação Santa Casa de Misericórdia do Pará, Brasil \\ E-mail: ellainelima11@gmail.com \\ Thaís de Oliveira Carvalho Granado Santos \\ ORCID: https://orcid.org/0000-0001-9496-4561 \\ Fundação Santa Casa de Misericórdia do Pará, Brasil \\ E-mail: thaisgranadosantos@gmail.com \\ Pilar Maria de Oliveira Moraes \\ ORCID: https://orcid.org/0000-0003-2817-4574 \\ Fundação Santa Casa de Misericórdia do Pará, Brasil \\ E-mail: pilarmoraesnutri@gmail.com \\ Xaene Maria Fernandes Duarte Mendonça \\ ORCID: https://orcid.org/0000-0002-0958-276X \\ Fundação Santa Casa de Misericórdia do Pará, Brasil \\ E-mail: xaenemaria@gmail.com
}

\begin{abstract}
Resumo
A amamentação é um importante período de proteção para a criança. No atual cenário pandêmico mundial de Covid19, ainda são poucas as pesquisas realizadas sobre gestantes e seus recém-nascidos, porém sabe-se que o risco de transmissão existe e deve ser levado em consideração no ato de amamentar. Por este motivo, esta revisão apresenta como pergunta norteadora: quais as evidências da literatura referentes ao aleitamento materno no contexto da Covid19? Esta pesquisa se caracteriza como Revisão Integrativa da Literatura. A busca de literaturas ocorreu no mês de março/abril de 2021e inicialmente identificou 171 artigos. Após a leitura de 22 resumos, foram selecionados 16 artigos os quais foram lidos integralmente. Depois da leitura analítica destes artigos, foram selecionados 10 artigos como objeto de estudo por apresentarem aspectos que respondiam à questão norteadora desta revisão. Por meio da análise dos artigos apresentados, pode-se perceber que a pandemia afetou a prática dos cuidados em saúde nos mais diversos seguimentos trazendo à tona a necessidade de adaptações nas condutas a serem tomadas frente às demandas de saúde dos indivíduos. Mediante a realização desta revisão integrativa de literatura foi possível encontrar as principais recomendações atuais referentes à amamentação no contexto da pandemia de Covid-19. Os principais achados nesta pesquisa corroboram com as recomendações de entidades de saúde nacionais e internacionais quanto à prática do aleitamento materno.
\end{abstract}

Palavras-chave: Aleitamento materno; Covid-19; Pandemia.

\begin{abstract}
Breastfeeding is an important period of protection for the child. In the current global pandemic scenario of Covid-19, there are few researches carried out on pregnant women and their newborns, but it is known that the risk of transmission exists and should be taken into account in the act of breastfeeding. For this reason, this review presents as a guiding question: what is the evidence in the literature regarding breastfeeding in the context of Covid-19? This research is characterized as an Integrative Literature Review. The literature search took place in March/April 2021 and initially identified 171 articles. After reading 22 abstracts, 16 articles were selected and read in full. After the analytical reading of these articles, 10 articles were selected as the object of study for presenting aspects that answered the guiding question of this review. Through the analysis of the articles presented, it can be seen that the pandemic affected the practice of health care in the most diverse segments, bringing to light the need for adaptations in the conduct to be taken in view of the health demands of individuals. Through this integrative literature review, it was possible to find the main current recommendations regarding breastfeeding in the context of the Covid-19
\end{abstract}


pandemic. The main findings in this research corroborate the recommendations of national and international health entities regarding the practice of breastfeeding.

Keywords: Breastfeeding; Covid-19; Pandemic.

\begin{abstract}
Resumen
La lactancia materna es un período importante de protección para el niño. En el actual escenario pandémico global de Covid-19, son pocas las investigaciones realizadas en mujeres embarazadas y sus recién nacidos, pero se sabe que el riesgo de transmisión existe y debe tenerse en cuenta en el acto de amamantar. Por esta razón, esta revisión se presenta como una pregunta orientadora: ¿cuál es la evidencia en la literatura sobre la lactancia materna en el contexto de Covid-19? Esta investigación se caracteriza como una Revisión de Literatura Integrativa. La búsqueda bibliográfica se llevó a cabo en marzo / abril de 2021 e inicialmente identificó 171 artículos. Después de leer 22 resúmenes, se seleccionaron 16 artículos y se leyeron en su totalidad. Luego de la lectura analítica de estos artículos, se seleccionaron 10 artículos como objeto de estudio para presentar aspectos que respondieron a la pregunta orientadora de esta revisión. A través del análisis de los artículos presentados, se puede apreciar que la pandemia afectó la práctica de la salud en los más diversos segmentos, poniendo de manifiesto la necesidad de adaptaciones en la conducta a tomar ante las demandas de salud de los individuos. A través de esta revisión integradora de la literatura, fue posible encontrar las principales recomendaciones actuales sobre la lactancia materna en el contexto de la pandemia Covid-19. Los principales hallazgos de esta investigación corroboran las recomendaciones de las entidades de salud nacionales e internacionales sobre la práctica de la lactancia materna.
\end{abstract}

Palabras clave: Lactancia materna; Covid-19; Pandemia.

\title{
1. Introdução
}

A amamentação é um importante período de proteção para a criança. O leite materno é o alimento mais completo para as necessidades da criança sendo perfeitamente adequado para demandas nutricionais nos primeiros anos de vida. É o único alimento que contém anticorpos e outras substâncias que protegem o lactente de infecções como diarreias, infecções respiratórias, infecções de ouvido e outras, e pode ainda prevenir o surgimento de várias doenças na vida adulta do indivíduo como asma, diabetes e obesidade, além de favorecer o desenvolvimento físico, emocional e a inteligência (Brasil, 2019).

O aleitamento materno é amplamente incentivado no Brasil e no mundo por meio das mais diferentes estratégias de promoção e proteção da amamentação. No entanto, existem algumas condições em que a prática do aleitamento materno não é recomendada, como às mães infectadas pelo HIV (human immunodeficiency vírus), HTLV1 e HTLV2 (human T-cell lymphotropic vírus) ou em uso de algum medicamento incompatível com a amamentação, como os quimioterápicos ou ainda para aquelas mulheres que fazem uso constante de álcool ou drogas ilícitas. Existem também algumas condições especiais em que o aleitamento materno deve ser executado com cuidados especiais ou deve haver interrupção temporária. Nestes casos, é de fundamental importância que a mãe seja acompanhada por profissionais de saúde capazes de orientar o melhor manejo na ocorrência desses eventos (Brasil, 2019).

No atual cenário pandêmico mundial de Covid-19, ainda são poucas as pesquisas realizadas sobre gestantes e seus recém-nascidos, porém sabe-se que o risco de transmissão existe e deve ser levado em consideração no ato de amamentar. Estudo realizado em 2020 com 311 recém-nascidos de mães com Covid-19 apontou que 3\% deles foram testados positivos para Covid-19 ainda na primeira semana de vida, no entanto, o meio de transmissão do Covid-19 não foi esclarecido (Rozycky \& Kotecha, 2020).

As pesquisas disponíveis até o momento sugerem que o leite materno não é fonte provável de transmissão, uma vez que as mães infectadas pela Covid-19 provavelmente já colonizaram seus filhos. Dessa forma, devido aos inúmeros benefícios advindos do leite materno aos lactentes, a recomendação das entidades de saúde nacionais e internacionais continua sendo manter a amamentação para as puérperas em bom estado geral, utilizando máscara de proteção e realizando a higienização das mãos antes e após cada mamada (Brasil, 2020).

Com essa questão em mente realizou-se esta revisão integrativa de literatura objetivando compreender: quais as evidências científicas da literatura referentes ao aleitamento materno no contexto da Covid-19? 


\section{Metodologia}

Esta pesquisa se caracteriza como Revisão Integrativa da Literatura. Para a elaboração desta revisão foram estabelecidas as seguintes etapas: a identificação do problema com definição da questão norteadora: Quais as evidências científicas sobre o aleitamento materno no contexto da Covid-19? Pesquisa por literaturas delimitadas às palavras-chave préestabelecidas, à base de dados e aos critérios estabelecidos para a seleção dos artigos; e análise crítica das pesquisas encontradas, discussão dos resultados e apresentação da revisão integrativa.

A busca de literaturas ocorreu no mês de março/abril de 2021. Foi estabelecido como critério de inclusão artigos em português e inglês, com data de publicação entre os últimos dois anos, 2020 e 2021, e que apresentassem conteúdo referente ao aleitamento materno no período da pandemia de Covid-19, indexados nas bases de dados LILACS (Literatura LatinoAmericana e do Caribe em Ciências da Saúde) e MEDLINE (Medical Literature Analysis and Retrieval System Online) estando estes presentes na Plataforma da Biblioteca Virtual de Saúde (BVS) e PubMed (National Library of Medicine). Para a realização da pesquisa, foram utilizadas combinações entre os descritores no DeCS (Descritores em Ciências de Saúde): Aleitamento materno, Covid-19, Pandemia e no idioma inglês no MesSH (Medical Subject Headings): Breastfeeding, Covid19 e Pandemic, relacionados entre si com o operador boleano e/and. A seleção dos artigos ocorreu pelos descritores presentes no título e no resumo.

Na busca realizada foram inicialmente identificados 171 artigos científicos presentes na plataforma da BVS para a leitura exploratória de seus títulos. Após esta leitura, foram descartados 149 artigos por seus temas não se assemelharem ao proposto por esta pesquisa. Totalizou-se então 22 artigos para leitura de seus resumos dos quais 06 estudos foram descartados por não atenderem aos critérios metodológicos impostos nesta pesquisa sendo selecionados 16 artigos, os quais foram lidos integralmente. Depois da leitura analítica destes artigos, foram selecionados 03 artigos da base de dados LILACS e 05 da base de dados MEDLINE. Foram ainda selecionados 02 artigos da base de dados PubMed como objeto de estudo por apresentarem aspectos que respondiam à questão norteadora desta revisão (Figura 1).

Figura 1- Fluxograma de coleta de dados.

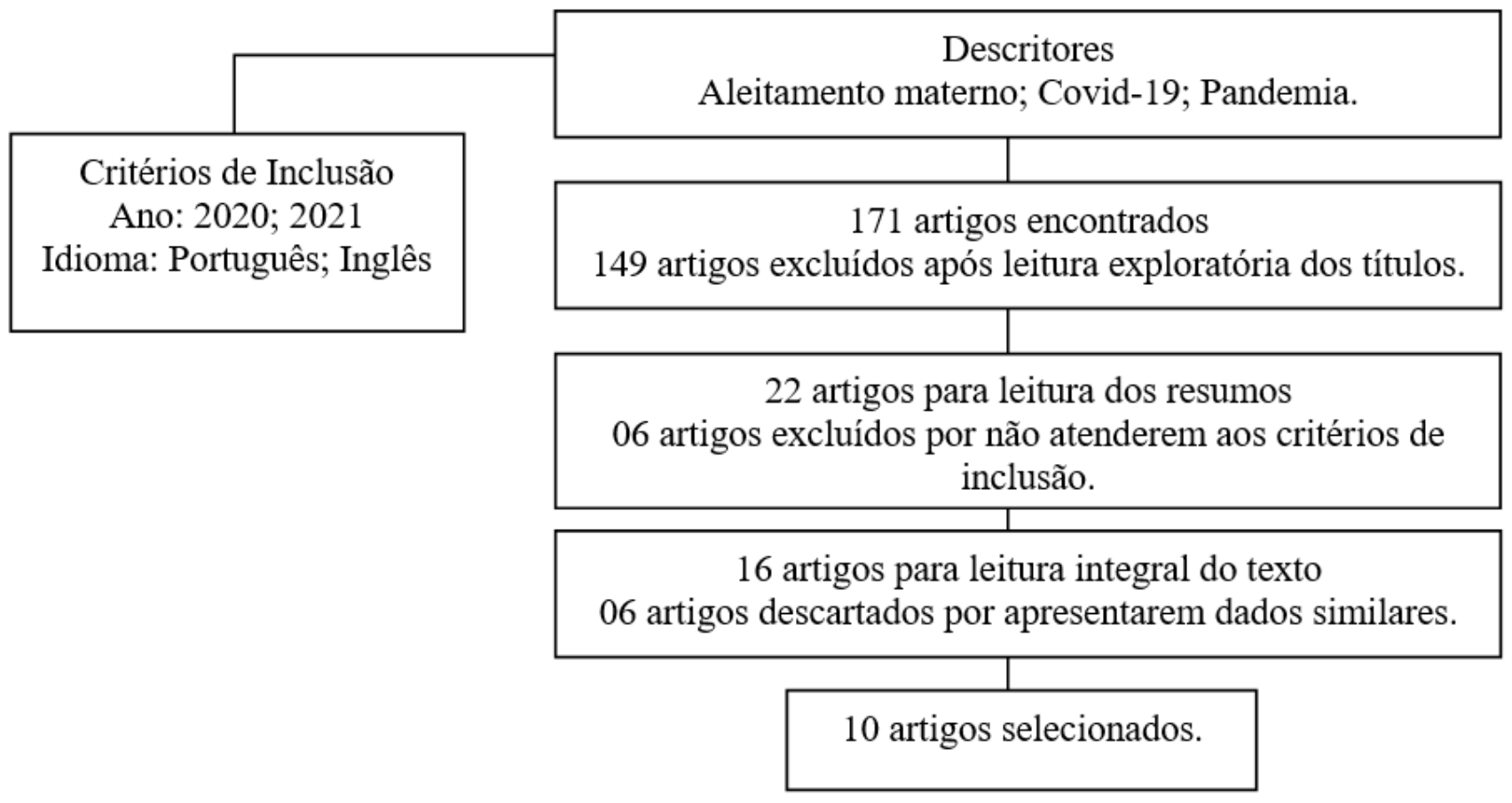

Fonte: Autores (2021). 


\section{Resultados}

Todas as publicações encontradas se concentram entre os anos de 2020 e 2021 dada a recente realidade pandêmica mundial. Dos artigos encontrados, 06 eram do ano de 2021 e 04 do ano de 2020 conforme mostra o Quadro 1.

Quadro 1- Artigos recuperados por base de busca, ano, título, descritores e tipo de estudo, do período de janeiro a abril de 2021, Brasil, 2021.

\begin{tabular}{|c|c|c|c|c|c|c|}
\hline $\mathbf{N}^{\circ}$ & ANO & BASE & TíTUlo & AUTORES & DESCRITORES & $\begin{array}{l}\text { TIPO DE } \\
\text { ESTUDO }\end{array}$ \\
\hline 01 & 2021 & LILACS & $\begin{array}{l}\text { A saúde materno-infantil no } \\
\text { contexto da pandemia de } \\
\text { Covid-19: } \quad \text { evidências, } \\
\text { recomendações e desafios. }\end{array}$ & $\begin{array}{l}\text { Cardoso, P. } \text { C., } \\
\text { Sousa, T. M. de, } \\
\text { Rocha, D. da } \text { S., } \\
\text { Menezes, L. R. D. } \\
\text { de, \& Santos, L. C. } \\
\text { dos. }\end{array}$ & $\begin{array}{l}\text { SARS-CoV-2; } \\
\text { Gravidez; Período pós- } \\
\text { parto; Aleitamento } \\
\text { materno; Criança. }\end{array}$ & $\begin{array}{l}\text { Revisão de } \\
\text { literatura }\end{array}$ \\
\hline 02 & 2021 & LILACS & $\begin{array}{lll}\text { Recomendações } & \text { para } \\
\text { assistência perinatal } & \text { no } \\
\text { contexto da pandemia } & \text { de } \\
\text { Covid-19. } & & \end{array}$ & $\begin{array}{l}\text { Oliveira, M. A. de, } \\
\text { Silva, N. É. F., } \\
\text { Pereira, J. de C. N., } \\
\text { Oliveira, M. A. de, } \\
\text { Silva, S. L. da, } \\
\text { Caminha, M. de F. } \\
\text { C., Cruz, R. de S. } \\
\text { B. L. C. }\end{array}$ & 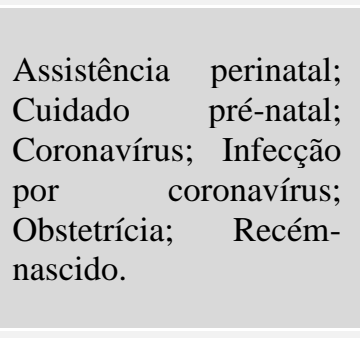 & $\begin{array}{l}\text { Revisão de } \\
\text { literatura }\end{array}$ \\
\hline 03 & 2020 & LILACS & $\begin{array}{l}\text { To breastfeed or not to } \\
\text { breastfeed? Lack of } \\
\text { evidence on the presence of } \\
\text { SARS-CoV-2 in breastmilk } \\
\text { of pregnant women with } \\
\text { Covid-19. }\end{array}$ & $\begin{array}{l}\text { Martins-Filho, P. } \\
\text { R., Santos, V. S., \& } \\
\text { Santos, H. P., Jr. }\end{array}$ & $\begin{array}{lr}\text { Coronavirus } & \text { infection; } \\
\text { virus } & \text { diseases; } \\
\text { pneumonia } & \text { viral; } \\
\text { pandemics; } & \text { SARS } \\
\text { virus; breast feeding }\end{array}$ & $\begin{array}{l}\text { Revisão } \\
\text { Sistemática }\end{array}$ \\
\hline 04 & 2020 & LILACS & $\begin{array}{l}\text { Guidance on breastfeeding } \\
\text { during the } \\
\text { pandemic. }\end{array}$ & $\begin{array}{l}\text { Calil, V. M. L. T., } \\
\text { Krebs, V. L. J., \& } \\
\text { Carvalho, W. B. de. }\end{array}$ & $\begin{array}{l}\text { Infant newborn; } \\
\text { Breastfeeding; } \\
\text { Neonatology; } \\
\text { Coronavirus; Covid-19 }\end{array}$ & $\begin{array}{l}\text { Revisão de } \\
\text { literatura }\end{array}$ \\
\hline 05 & 2020 & LILACS & $\begin{array}{l}\text { Covid-19 and newborn } \\
\text { health: systematic review. }\end{array}$ & $\begin{array}{l}\text { Duran, P., Berman, } \\
\text { S., Niermeyer, S., } \\
\text { Jaenisch, T., T., } \\
\text { Forster, T., Gomez } \\
\text { Ponce de Leon, R., } \\
\text { Serruya, S. }\end{array}$ & $\begin{array}{lr}\text { Coronavirus } & \text { infection; } \\
\text { virus } & \text { diseases; } \\
\text { pandemics; } & \text { SARS } \\
\text { virus; congenital, } & \text { hereditary, } \\
\text { neonatal diseases } & \text { and } \\
\text { abnormalities; } & \\
\text { infectious disease } & \text { transmission vertical. }\end{array}$ & $\begin{array}{l}\text { Revisão } \\
\text { Sistemática }\end{array}$ \\
\hline 06 & 2021 & MEDLINE & $\begin{array}{l}\text { The impact of coronavirus } \\
\text { outbreak on breastfeeding } \\
\text { guidelines among Brazilian } \\
\text { hospitals and maternity } \\
\text { services: a crosssectional } \\
\text { study. }\end{array}$ & $\begin{array}{l}\text { Gonçalves-Ferri, } \\
\text { W. A., Pereira- } \\
\text { Cellini, F. M., } \\
\text { Coca, K., Aragon, } \\
\text { D. C., Nader, P., } \\
\text { Lyra, J. C. }\end{array}$ & $\begin{array}{l}\text { Breastfeeding; } \text { Covid- } \\
\text { 19; Public health; Skin- } \\
\text { to-skin; } \quad \text { Brazil; } \\
\text { Breastfeeding } \\
\text { guidelines; } \\
\text { Breastfeeding } \\
\text { Practices; Milk bank. }\end{array}$ & $\begin{array}{c}\text { Estudo } \\
\text { transversal } \\
\text { descritivo } \\
\text { multicêntrico }\end{array}$ \\
\hline
\end{tabular}


continuação

\begin{tabular}{|c|c|c|c|c|c|c|}
\hline $\mathbf{N}^{\mathbf{o}}$ & ANO & BASE & TÍTULO & AUTORES & DESCRITORES & $\begin{array}{l}\text { TIPO DE } \\
\text { ESTUDO }\end{array}$ \\
\hline 07 & 2021 & MEDLINE & $\begin{array}{l}\text { The impact of the Covid- } 19 \\
\text { pandemic on maternal and } \\
\text { perinatal health: a scoping } \\
\text { review. }\end{array}$ & $\begin{array}{l}\text { Kotlar, B., Gerson, } \\
\text { E., Petrillo, S., } \\
\text { Langer, A., \& } \\
\text { Tiemeier, H. }\end{array}$ & $\begin{array}{l}\text { Covid-19; SARS-CoV- } \\
\text { 2; Maternal health; } \\
\text { Newborn health; } \\
\text { Maternal-child } \\
\text { transmission; Mental } \\
\text { health; Gender equity. }\end{array}$ & $\begin{array}{c}\text { Revisão de } \\
\text { escopo }\end{array}$ \\
\hline 08 & 2021 & MEDLINE & $\begin{array}{l}\text { Should Covid-19 Mother } \\
\text { Breastfeed her Newborn } \\
\text { Child? A Literature Review } \\
\text { on the Safety of } \\
\text { breastfeeding for Pregnant } \\
\text { Women with Covid-19. }\end{array}$ & Bhatt H. & $\begin{array}{l}\text { Covid-19; } \\
\text { Breastfeeding; Breast } \\
\text { milk; Pregnancy; } \\
\text { SARS-CoV-2; Infant; } \\
\text { Newborn. }\end{array}$ & $\begin{array}{c}\text { Revisão } \\
\text { Sistemática }\end{array}$ \\
\hline 09 & 2021 & MEDLINE & $\begin{array}{l}\text { Experiences } \\
\text { breastfeeding during Covid- } \\
\text { 19: Lessons for future } \\
\text { practical and emotional } \\
\text { support. }\end{array}$ & $\begin{array}{l}\text { Brown A; Shenker } \\
\text { N. }\end{array}$ & $\begin{array}{l}\text { Breastfeeding; } \\
\text { breastfeeding support; } \\
\text { Covid-19; formula } \\
\text { feeding; lockdown; } \\
\text { maternal mentalhealth. }\end{array}$ & $\begin{array}{l}\text { Pesquisa } \\
\text { qualitativa } \\
\text { descritiva }\end{array}$ \\
\hline 10 & 2020 & MEDLINE & $\begin{array}{l}\text { Pregnancy and } \\
\text { Breastfeeding During Covid } \\
-19 \text { Pandemic: A Systematic } \\
\text { Review of Published } \\
\text { Pregnancy Cases. }\end{array}$ & $\begin{array}{lr}\text { Rodrigues, } & \text { C., } \\
\text { Baía, } & \text { I., } \\
\text { Domingues, R., } \quad \text { \& } \\
\text { Barros, H. }\end{array}$ & $\begin{array}{l}\text { Covid-19; pregnancy; } \\
\text { vertical transmission; } \\
\text { perinatal outcomes; } \\
\text { breastfeeding }\end{array}$ & $\begin{array}{c}\text { Revisão } \\
\text { sistemática }\end{array}$ \\
\hline
\end{tabular}

Quanto ao tipo de estudo, 04 eram do tipo Revisão Sistemática, 03 do tipo Revisão de literatura, 01 se caracterizava como Revisão de Escopo, 01 como Estudo Transversal Descritivo Multicêntrico e 01 como Pesquisa Qualitativa Descritiva. A seguir, Quadro 02 apresenta a distribuição dos estudos por objetivos e principais resultados e conclusões.

Quadro 2- Artigos selecionados para análise segundo, objetivos, resultados e conclusões, Brasil, 2021.

\begin{tabular}{|c|c|c|c|}
\hline $\mathbf{N}^{\mathbf{o}}$ & TÍTULO & OBJETIVOS & RESULTADOS \\
\hline 01 & $\begin{array}{l}\text { A saúde materno- } \\
\text { infantil no } \\
\text { contexto } \\
\text { pandemia } \\
\text { Covid-19: } \\
\text { evidências, } \\
\text { recomendações } \\
\text { desafios. }\end{array}$ & $\begin{array}{l}\text { Apresentar as } \\
\text { principais } \\
\text { evidências, } \\
\text { recomendações e } \\
\text { desafios à saúde } \\
\text { materno-infantil no } \\
\text { contexto da } \\
\text { pandemia } \\
\text { Covid-19. }\end{array}$ & $\begin{array}{l}\text { Ainda não existem informações } \\
\text { claras sobre a presença de } \\
\text { anticorpos específicos para } \\
\text { SARS-CoV2 no leite materno. } \\
\text { Considerando os benefícios do } \\
\text { leite materno para o sistema } \\
\text { imunológico, crescimento e } \\
\text { desenvolvimento infantil, manter } \\
\text { a amamentação sob os cuidados } \\
\text { higiênicos estabelecidos torna-se } \\
\text { a ação mais prudente no contexto } \\
\text { da promoção da saúde materno- } \\
\text { infantil. }\end{array}$ \\
\hline
\end{tabular}

\section{CONCLUSÕES}

A conduta adotada deve ser de caráter individual, abrangendo todos os aspectos de saúde do binômio mãe-filho, estimando os riscos e benefícios de cada decisão. Até o momento, reconhece-se que a amamentação mantida, desde que assegurados os cuidados higiênicosanitários. O isolamento com separação do contato mãe-filho, sem amamentação será elegível para casos em que o quadro clínico da mãe ou da criança seja crítico. 
continuação

\begin{tabular}{|c|c|}
\hline $\mathbf{N}^{\mathbf{0}}$ & TÍTULO \\
\hline 02 & \begin{tabular}{lr}
\multicolumn{2}{l}{ Recomendações } \\
para assistência \\
perinatal no \\
contexto & da \\
pandemia & de \\
Covid-19. &
\end{tabular} \\
\hline
\end{tabular}

To breastfeed or not to breastfeed? Lack of evidence on the presence of SARS-CoV-2 in breastmilk of pregnant women with Covid-19.

Guidance on breastfeeding during the Covid19 pandemic.

\section{Fornecer}

orientações sobre amamentação para mães suspeitas ou confirmadas para Covid-19.

Covid-19 and newborn health: systematic review.

The impact of coronavirus outbreak on breastfeeding guidelines among Brazilian hospitals and maternity services: a crosssectional study.

expostos ao SARSCoV-2.

Analisar como os hospitais brasileiros e maternidades promovem e apoiam mães suspeitas ou diagnosticadas com Covid-19.

\section{RESULTADOS}

Apresentar as
recomendações
científicas para a
atenção perinatal
no contexto da
pandemia de
Covid-19.

Apresentar

as evidências atuais relacionadas a presença de SARSCoV-2 no leite materno de gestantes positivo para Covid-19.
Triagem e testagem dos casos suspeitos, desencorajamento do contato pele a pele e amamentação na primeira hora de vida.

\section{CONCLUSÕES}

Evidências científicas baseadas em estudos com desenhos metodológicos e análises mais robustas são necessárias para nortear a assistência perinatal livre de danos no contexto da pandemia por Covid-19.

Dados ainda limitados para manutenção da amamentação em caso de mulheres com Covid-19. Não á restrições para uso de leite de banco de leite humano.
Foram analisadas 20 publicações recentes sobre aleitamento materno, Covid-19 e sua transmissão pelo leite. Foram apresentadas as possíveis opções maternas em relação ao aleitamento e suas consequências para o binômio mãe-filho.

O sangue do cordão umbilical, a placenta ou o líquido amniótico foram analisados em cinco estudos, não tendo sido relatados resultados positivos. Estudos que analisaram leite materno mostraram resultados negativos para SARS-CoV-2.
No Brasil, os hospitais não seguem as recomendações para promover a amamentação na primeira hora de vida. Não há diretrizes de alta individualizadas e há falta de apoio de saúde no ambiente domiciliar.
Todas as opções maternas em relação à amamentação são justificáveis, porque a infecção por Covid-19 ainda é pouco conhecida. Porém, as puérperas e seus familiares devem ser muito bem orientados, realizando uma opção consciente e baseada nas informações disponíveis na literatura até o momento.

Dada à escassez de estudos, neste momento a transmissão vertical não pode ser confirmada ou excluída. A literatura atual não apoia a abstenção da amamentação ou a separação dos recém-nascidos das suas mães.

É necessário estabelecimento de condutas padronizadas para proteger a amamentação na atual pandemia. 
continuação

\begin{tabular}{|c|c|c|c|}
\hline $\mathbf{N}^{\mathbf{o}}$ & TÍTULO & OBJETIVOS & RESULTADOS \\
\hline 07 & $\begin{array}{l}\text { The impact of the } \\
\text { Covid-19 } \\
\text { pandemic on } \\
\text { maternal and } \\
\text { perinatal health: a } \\
\text { scoping review. }\end{array}$ & $\begin{array}{l}\text { Fornecer uma visão } \\
\text { abrangente sobre a } \\
\text { o impacto da } \\
\text { pandemia de } \\
\text { Covid-19 na saúde } \\
\text { materna e neonatal. }\end{array}$ & $\begin{array}{l}\text { Transmissão intrauterina e pelo } \\
\text { leite materno foram improváveis. } \\
\text { Recomendações sobre sala de } \\
\text { parto e amamentação variaram. } \\
\text { Visitas para cuidados neonatais } \\
\text { diminuíram; Sistema de saúde } \\
\text { sobrecarregado. }\end{array}$ \\
\hline
\end{tabular}

\begin{tabular}{|c|c|c|c|}
\hline 08 & $\begin{array}{l}\text { Should Covid-19 } \\
\text { Mother } \\
\text { Breastfeed her } \\
\text { Newborn Child? } \\
\text { A Literature } \\
\text { Review on the } \\
\text { Safety of } \\
\text { reastfeeding for } \\
\text { Pregnant Women } \\
\text { with Covid-19. }\end{array}$ & $\begin{array}{lr}\text { Examinar } & \text { as } \\
\text { evidências } & \\
\text { disponíveis } & \text { sobre } \\
\text { os riscos de } & \text { dransmissão de } \\
\text { Covid-19 através } \\
\text { da amamentação. }\end{array}$ & $\begin{array}{l}\text { Dados limitados a respeito do } \\
\text { tema, porém os mesmos sugerem } \\
\text { que não há risco de contaminação } \\
\text { por leite materno. Anticorpos } \\
\text { virais poderiam passar para o } \\
\text { recém-nascido de mães positivas } \\
\text { para o vírus através do leite } \\
\text { materno, mas as evidências ainda } \\
\text { são muito limitadas. }\end{array}$ \\
\hline 09 & $\begin{array}{l}\text { Experiences of } \\
\text { breastfeeding } \\
\text { during Covid-19: } \\
\text { Lessons for future } \\
\text { practical and } \\
\text { emotional } \\
\text { support. }\end{array}$ & $\begin{array}{l}\text { Evidenciar } \quad \text { o } \\
\text { impacto } \quad \text { da } \\
\text { pandemia sobre a } \\
\text { amamentação. }\end{array}$ & $\begin{array}{l}41,8 \% \text { das mães sentiram que o } \\
\text { lockdown protegeu a prática da } \\
\text { amamentação e } 27 \% \text { das mães } \\
\text { precisaram de suporte para } \\
\text { manter a amamentação, porém o } \\
\text { lockdown impediu que } \\
\text { alcançassem apoio para o mesmo } \\
\text { fazendo com que a amamentação } \\
\text { fosse interrompida. }\end{array}$ \\
\hline 10 & $\begin{array}{l}\text { Pregnancy and } \\
\text { Breastfeeding } \\
\text { During Covid-19 } \\
\text { Pandemic: A } \\
\text { Systematic } \\
\text { Review of } \\
\text { Published } \\
\text { Pregnancy Cases. }\end{array}$ & $\begin{array}{lr}\text { Conhecer } & \text { o } \\
\text { impacto da } & \text { Covid- } \\
\text { 19 sobre a gestação } \\
\text { e descrever } & \text { os } \\
\text { resultados } & \\
\text { publicados } & \text { de } \\
\text { gestação } & \text { de } \\
\text { mulheres } & \text { com } \\
\text { diagnóstico } & \text { de } \\
\text { Covid-19. } & \end{array}$ & $\begin{array}{l}\text { Quatro amostras de leite materno, } \\
\text { de um total de } 92 \text { casos } \\
\text { analisados, foram positivas para } \\
\text { SARS-CoV-2. }\end{array}$ \\
\hline
\end{tabular}

Fonte: Autores (2021).

\section{CONCLUSÕES}

Gestantes não estão mais susceptíveis à infecção por Covid-19 do que outras pessoas, no entanto, no caso de contrair o vírus, gestantes podem enfrentar situações mais adversas tanto clínica quanto socioeconômicas. É necessário mais estudos a respeito do tema.

Com base nos benefícios da amamentação, a mesma deve ser incentivada por profissionais de saúde. Cuidados devem ser tomados para prevenir a transmissão de Covid-19 por gotículas aos bebês durante a amamentação em caso de mães positivas para o vírus.

Os resultados foram importantes para entender como prestar suporte a amamentação em período de lockdown.

\begin{abstract}
Evidências emergentes sugerem que a transmissão vertical é possível, no entanto, ainda há um número limitado de casos relatados com amostras intraparto.

Informação, aconselhamento e monitoramento adequado são essenciais para prevenir e gerenciar efeitos adversos da infecção por SARS-CoV-2 durante a gravidez.
\end{abstract}

\section{Discussão}

As dimensões da pandemia de Covid-19 têm gerado grandes impactos de ordem sanitária, social, econômica e política. Até o primeiro trimestre de 2021, a Organização Mundial da Saúde (OMS) registrou mais de 126 milhões de casos e mais de 2,7 milhões de mortes em todo o mundo, com aumento significativo nos últimos meses causados pela segunda onda da pandemia que atinge diversos países, entre eles, o Brasil, que no referido período responde pelo maior número de novos casos 
da doença e de novas mortes em todo o planeta (WHO, 2021).

A partir da análise dos artigos selecionados nesta revisão integrativa pode-se perceber que a pandemia afetou a prática dos cuidados em saúde nos mais diversos seguimentos trazendo à tona a necessidade de adaptações nas condutas a serem tomadas frente às demandas de saúde dos indivíduos.

A World Health Organization em uma de suas primeiras recomendações trouxe à luz a importância da reorganização dos diferentes serviços de saúde para que estes possam desempenhar plenamente suas funções no contexto da pandemia. Uma de suas orientações diz respeito à criação de novos pontos de acesso ao sistema de saúde, com especial importância à via remota, a qual, se bem planejada, permite a manutenção do distanciamento social e dos cuidados de saúde. Dentre as recomendações para o teleatendimento, a OMS sugere que os atendentes desta modalidade sejam treinados na utilização de protocolos que permitam distinguir casos leves, moderados e graves e os corretos encaminhamentos em cada uma destas situações (WHO, 2020).

O estudo 09, intitulado Experiences of breastfeeding during COVID-19: Lessons for future practical and emotional support apresentado nesta revisão integrativa, mostrou os impactos da pandemia sobre a amamentação. Neste estudo, evidenciou-se que a principal razão para que as mães parassem de amamentar durante a pandemia foi a falta de suporte profissional. O estudo mostrou ainda que 70,3\% das participantes pararam de amamentar seus bebês pela impossibilidade de suporte pessoal, 20,9\% por não saber se seria seguro amamentar e apenas 6,5\% por apresentar sintomas de Covid-19. Esses achados sinalizam a importante necessidade dos profissionais de saúde estarem adequadamente aptos a orientarem as condutas para manutenção da amamentação, frente a esta nova realidade mundial.

Os profissionais de saúde dos serviços de Atenção Primária a Saúde (APS) devem manter o acesso aos cuidados de saúde para outros agravos durante a pandemia através da continuidade de ações preventivas tais como vacinação, acompanhamento de pacientes portadores de doenças crônicas, gestantes e lactentes, entre outras. A ausência dessas ações na vigência da pandemia poderia resultar em aumento da morbimortalidade por outras causas ampliando os impactos de saúde pública causados pela doença (Nacoti, et. al., 2020).

Frente a um cenário mundial pandêmico onde a principal recomendação para diminuir a propagação do vírus de SARS-CoV-2 é a de distanciamento social, os cuidados em saúde necessitam de adaptação. Observa-se uma tendência mundial no uso de tecnologias digitais de informação e comunicação que auxiliem no enfrentamento ao Coronavírus (Kummitha, 2020).

O uso de ferramentas digitais em meio ao contexto da Covid-19 além de favorecer a disseminação rápida de informações sobre a Covid-19 também permite a manutenção dos cuidados necessários para a prevenção da doença uma vez que é de consenso mundial que o controle da pandemia e a prevenção da infecção são dados por meio do distanciamento social (OPAS, 2020)

O Center for Disease Control and Prevention (CDC), órgão de vigilância do governo dos Estados Unidos, em sua diretriz sobre amamentação para mães positivas ou em investigação para a Covid-19, embasados nos dados disponíveis até o momento, sugerem que o leite materno não é fonte provável de transmissão e que é a melhor fonte de nutrição para os recémnascidos por conferir proteção contra inúmeras doenças, mantem a recomendação de que puérperas em bom estado geral devem dar continuidade a amamentação utilizando máscaras de proteção e realizando a higienização das mãos antes e após a mamada (CDC, 2020).

O Ministério da Saúde (MS) em parceria com entidades de saúde nacionais recomenda que, nos casos em que a mulher estiver infectada por SARS-Cov-2 e não se sentir segura em amamentar, tendo em vista que a mesma pode transmitir o vírus através de gotículas respiratórias, o leite cru pode ser uma alternativa, desde que ofertado após a extração manual ou mecânica, com uso individual de bombas e rotina de higienização dos seios e das mãos de pelo menos 20 segundos, antes e 
após a extração do leite, e uso de máscara facial que cubra completamente boca e nariz (Brasil, 2020).

Até o momento não se sabe sobre o efeito da pasteurização sobre o SARS-CoV-2, mas à semelhança de outros vírus, é possível que seja inativado. Entretanto, a Rede Global de bancos de Leite Humano divulgou nota técnica acerca das condutas para doação de leite materno aos bancos de leite humanos no contexto da infecção de coronavírus. A rede contraindica a doação de leite por mulheres com sintomas compatíveis com síndrome gripal, infecção respiratória ou confirmação de caso de Covid-19. A contraindicação é estendida às mulheres que tenham contato domiciliar de casos com síndrome gripal ou caso confirmado de Covid-19 (Brasil, 2020).

A maioria dos estudos apresentados nesta revisão mostrou conclusões concordantes com as recomendações do CDC e do MS. No entanto, é importante salientar as orientações advindas do estudo 01, que indica que as condutas a serem adotadas no binômio mãe-filho devem ser individualizadas, a fim de minimizar as consequências da pandemia no âmbito da saúde materno-infantil.

\section{Conclusão}

Mediante a realização desta revisão integrativa de literatura foi possível encontrar as principais recomendações atuais referentes à amamentação no contexto da pandemia de Covid-19.

Os principais achados nesta pesquisa corroboram com as recomendações de entidades de saúde nacionais e internacionais quanto à prática do aleitamento materno.

Apesar das entidades de saúde já terem posicionamento referentes às condutas a serem adotadas para manutenção da amamentação frente a esta realidade sanitária mundial, constatou-se que a pandemia tem gerado impactos no aleitamento materno principalmente devido à falta de orientação profissional adequada.

Sendo assim, fazem-se necessárias constantes ações de promoção do aleitamento materno em meio à pandemia de Covid-19, tanto referentes à capacitação profissional, quanto à implementação de práticas que alcancem as mães que estão vivendo ou viverão esse momento.

\section{Referências}

Bhatt, H. (2021). Should COVID-19 mother breastfeed her newborn child? A literature review on the safety of breastfeeding for pregnant women with COVID-19. Current Nutrition Reports, 10(1), 71-75.

Brasil. Ministério da Saúde. Secretaria de Atenção Primaria à Saúde. Departamento de Ações Programáticas Estratégicas. (2020). NOTA TÉCNICA No 7/2020-DAPES/SAPS/MS. Recuperado em 06 de abril de 2021, de: http://www.saude.df.gov.br/wp-conteudo/uploads/2018/02/SEI_MS-0014033399-NotaTe\%CC\%81cnica-Aleitamento-e-COVID.pdf.

Brasil. Ministério da Saúde. Secretaria de Atenção Primaria à Saúde. Departamento de Promoção da Saúde. (2019). Guia alimentar para crianças brasileiras menores de 2 anos. Brasília: Ministério da Saúde.

Brasil. Ministério da Saúde. Secretaria de Atenção Primaria à Saúde. (2020). NOTA TÉCNICA No 5/2020-COCAM/CGCIVI/DAPES/SAPS/MS. Recuperado em 06 de abril de 2021, de: https://www.conasems.org.br/wp-content/uploads/2020/03/notatecnicaaleitamento30mar2020COVID-19.pdf

Brown, A., \& Shenker, N. (2021). Experiences of breastfeeding during COVID-19: Lessons for future practical and emotional support. Maternal \& Child Nutrition, 17(1), e13088.

Calil, V. M. L. T., Krebs, V. L. J., \& Carvalho, W. B. de. (2020). Guidance on breastfeeding during the Covid-19 pandemic. Revista Da Associacao Medica Brasileira (1992), 66(4), 541-546.

Cardoso, P. C., Sousa, T. M. de, Rocha, D. da S., Menezes, L. R. D. de, \& Santos, L. C. dos. (2021). Maternal and child health in the context of COVID-19 pandemic: evidence, recommendations and challenges. Revista Brasileira de Saúde Materno Infantil, 21(suppl 1), $213-220$.

Center for Disease Control and Prevention. (2020). Care for Breastfeeding Women Interim Guidance on Breastfeeding and Breast Milk Feeds in the Context of COVID-19. Recuperado em 06 de abril de 2021, de: https://www.cdc.gov/coronavirus/2019-ncov/hcp/care-for-breastfeeding-women.html.

Duran, P., Berman, S., Niermeyer, S., Jaenisch, T., Forster, T., Gomez Ponce de Leon, R., Serruya, S. (2020). COVID-19 and newborn health: systematic review. Revista Panamericana de Salud Publica [Pan American Journal of Public Health], 44, e 54. 
Gonçalves-Ferri, W. A., Pereira-Cellini, F. M., Coca, K., Aragon, D. C., Nader, P., Lyra, J. C., BRACOVID Project Collaborative Group. (2021). The impact of coronavirus outbreak on breastfeeding guidelines among Brazilian hospitals and maternity services: a cross-sectional study. International Breastfeeding Journal, 16(1), 30 .

Kotlar, B., Gerson, E., Petrillo, S., Langer, A., \& Tiemeier, H. (2021). The impact of the COVID-19 pandemic on maternal and perinatal health: a scoping review. Reproductive Health, 18(1), 10.

Kummitha, R. K. R. (2020). Smart technologies for fighting pandemics: The techno- and human- driven approaches in controlling the virus transmission. Government Information Quarterly, 37(3), 101481

Martins-Filho, P. R., Santos, V. S., \& Santos, H. P., Jr. (2020). To breastfeed or not to breastfeed? Lack of evidence on the presence of SARS-CoV-2 in breastmilk of pregnant women with COVID-19. Revista Panamericana de Salud Publica [Pan American Journal of Public Health], 44, e59.

Nacoti M., Ciocca A., Giupponi A., Brambillasca P., Lussana F., Pisano M., Montaguti C. (n.d.). At the epicenter of the covid-19 pandemic and humanitarian crises in Italy: Changing perspectives on preparation and mitigation. Catalyst Non-Issue Content, 1(2). doi:10.1056/CAT.20.0080.

Oliveira, M. A. de, Silva, N. É. F., Pereira, J. de C. N., Oliveira, M. A. de, Silva, S. L. da, Caminha, M. de F. C., Cruz, R. de S. B. L. C. (2021). Recommendations for perinatal care in the context of the COVID-19 pandemic. Revista Brasileira de Saúde Materno Infantil, 21(suppl 1), 65-75.

Organização Pan-Americana de Saúde. (2020.). considerações sobre medidas de distanciamento social e medidas relacionadas com as viagens no contexto da resposta à pandemia de covid-19. https://iris.paho.org/bitstream/handle/10665.2/52045/OPASBRACOVID1920039_por.pdf?sequence=9\&isAllowed=y

Rodrigues, C., Baía, I., Domingues, R., \& Barros, H. (2020). Pregnancy and breastfeeding during COVID-19 pandemic: A systematic review of published pregnancy cases. Frontiers in Public Health, 8, 558144

Rozycki, H. J., \& Kotecha, S. (2020). Covid-19 in pregnant women and babies: What pediatricians need to know. Pediatric Respiratory Reviews, 35 , $31-37$.

World Health Organization. (2020). Operational considerations for case management of COVID-19 in health facility and community: interim guidance, 19 March 2020. World Health Organization.

World Health Organization. (2021.). Weekly epidemiological update on COVID-19 - 30 March 2021. Recuperado em 06 de abril de 2021, de: https://www.who.int/publications/m/item/weekly-epidemiological-update-on-covid-19---31-march-2021. 